\title{
Design of digital games in health sciences education
}

\author{
S Titus, ${ }^{1} \mathrm{PhD} ; \mathrm{D}$ Ng'ambi, ${ }^{2} \mathrm{PhD}$ \\ ${ }^{1}$ Interprofessional Education Unit, Faculty of Community and Health Sciences, University of the Western Cape, Cape Town, South Africa \\ ${ }^{2}$ School of Education, University of Cape Town, South Africa
}

Corresponding author: S Titus (sititus@uwc.ac.za)

\section{Why was this idea necessary (problem)?}

The use of digital games to mitigate some of the challenges of engagement and active participation has been successful in some countries. ${ }^{[1]}$ While games are equated with fun, they should also be designed to provide learning opportunities that allow students to reflect, construct knowledge and test hypotheses. However, the design of digital games remains a challenge within course design, and has remained under-explored in historically disadvantaged institutions in South Africa (SA).

\section{What was tried (approach)?}

Using design-based research, a qualitative pilot study was conducted as part of the design and implementation of an interactive learning environment, using a self-developed sport psychology trivia/quiz digital game in a health science discipline in SA. The game was designed to be played in groups of five players on each team, with the purpose of facilitating cross-cultural learning. Players formed two small groups and played three head-to-head rounds to determine whether the beta version of the digital game would be a beneficial tool to mediate crosscultural engagement before implementation in a large classroom. The digital game was designed so that content from other cognate health science disciplines could be embedded in the database of the game. It could be played on a laptop or a mobile device such as an iPad or an Android-enabled smartphone or tablet. The beta version of the game requires teams to answer as many questions as possible correctly within 30 seconds. For each game round, there is a group leader who controls the game and reads the questions. His/her group members assist in answering the questions. Groups that answer the most questions correctly, score the highest points. Each gaming session lasts 7 minutes, after which a new leader is selected until each member has had a leadership opportunity. Five players who tested the game participated in a focus group discussion.

\section{What lessons were learnt (outcome)?}

There are at least two major lessons to consider when developing games in health sciences education, i.e. game design and group dynamics. Game design takes into account time and academic challenge, i.e. games should be designed with degrees of difficulty so that students are able to improve their competence with subject matter embedded in the digital game. Lack of time resulted in anxiety and therefore time allocation had to be adjusted in the final game. Group dynamics takes into account that groups should be randomised to avoid the formation of cliques. This, coupled with small groups of not more than five players per team, allows for better productivity, interaction, integration and group cohesion. These are integral design features to be embedded in a digital game for learning to ensure interaction, engagement and co-construction of knowledge in a fun and meaningful way. This innovation offered new insight into the development of a digital game to facilitate engagement in the health sciences, and it is a novel way to support a current blended learning environment.

Declaration. The article was based on a study done by ST in partial fulfilment of her $\mathrm{PhD}$ thesis.

Acknowledgements. Ethical approval for this study was obtained from the University of Cape Town Doctoral Degrees Board (ref. no. C0098).

Author contributions. Both authors contributed equally to the article.

Funding. The study was supported by the Deputy Vice-Chancellor (Academic), University of the Western Cape, and the National Research Foundation, South Africa. Conflicts of interest. None. 1. Giannakas F, Kambourakis G, Papasalouros A, Gritzalis S. A critical review of 13 years of mobile game-based
learning. Educ Technol Res Develop 2018;66(2):341-384. https://doi.org/10.1007/s11423-017-9552-z

Accepted 1 July 2019

Afr J Health Professions Educ 2019;11(3):74. https://doi.org/10.7196/AJHPE.2019.v11i3.1190 